\title{
Unilateral Arm Urticaria Presenting as a Paraneoplastic Manifestation of Metachronous Bilateral Breast Cancer
}

\author{
Pashtoon Murtaza Kasi $^{\mathrm{a}}$ Tina J. Hieken ${ }^{\mathrm{b}}$ Tufia C. Haddad ${ }^{\mathrm{a}}$ \\ ${ }^{a}$ Department of Oncology, Mayo Clinic, and ${ }^{b}$ Department of Surgery, College of Medicine, \\ Mayo Clinic, Rochester, Minn., USA
}

\section{Key Words}

Paraneoplastic syndromes · Urticaria - Dermatological symptoms · Neurological complications · Breast cancer · Occult malignancy $\cdot$ Rash $\cdot$ Adenocarcinoma

\begin{abstract}
Various paraneoplastic syndromes (PNS) are reported to be associated with breast cancer and can range from mild dermatological symptoms to severe neurological complications. Neurological and dermatological manifestations tend to be the more commonly seen paraneoplastic manifestations, albeit both are relatively rare. Diagnosis of the underlying malignancy is often delayed since the presence and severity of paraneoplastic manifestations are not dependent on the tumor size or stage. Herein, we describe a unique case of unilateral arm urticaria presenting as a paraneoplastic manifestation of metachronous bilateral breast cancer. Similar reports and other PNS associated with breast cancer are described. Recognition of PNS associated with underlying malignancies and age-appropriate screening can facilitate diagnosis of the underlying occult malignancy. Resection of the underlying malignancy can lead to resolution and/or improvement of the PNS for some patients.

(C) 2016 The Author(s)

Published by S. Karger AG, Basel

\section{Introduction}

Breast cancer is one of the malignancies that can present with varied paraneoplastic manifestations. Herein, we describe a unique case of unilateral arm urticaria presenting as a paraneoplastic manifestation of metachronous bilateral breast cancer. Similar reports and other paraneoplastic syndromes (PNS) associated with breast cancer are described.
\end{abstract}

\section{KARGER 125/s $\quad \begin{aligned} & \text { Pashtoon Murtaza Kasi, MD } \\ & \text { Department of Oncology, Mayo Clinic }\end{aligned}$ \\ 200 First Street SW \\ Rochester, MN 55905 (USA) \\ E-Mail kasi.pashtoon@mayo.edu}




\section{Case Reports in Oncology}

Kasi et al: Unilateral Arm Urticaria Presenting as a Paraneoplastic Manifestation of Metachronous Bilateral Breast Cancer

\section{Case Presentation}

A 49-year-old premenopausal woman in good health with no chronic disease initially established care at our clinic in February 2013 due to an abnormal mammogram. The screening mammogram revealed abnormal calcifications in the superior lateral and superior medial quadrants of the left breast. Review of systems was notable only for a 12-week history of unilateral left arm urticaria of indeterminate etiology. She had no prior history of urticaria or other dermatological conditions and she denied any new contact or exposures to the left arm. Her physical examination, including clinical breast exam, was normal. Only one of the two areas of calcifications, over a span of $4 \mathrm{~mm}$ at the 1:00 position, was reproducible on the diagnostic mammogram. Stereotactic-guided biopsy was consistent with atypical ductal hyperplasia with calcifications as well as atypical lobular hyperplasia. A subsequent excisional left breast biopsy by seed localization showed multifocal, grade 1 invasive lobular carcinoma with 3 foci of disease, the largest of which measured $1.2 \mathrm{~cm}$. Postoperatively, breast MRI and second-look ultrasound suggested residual foci of disease. The patient therefore elected treatment with a left skin-sparing mastectomy with immediate breast reconstruction and left axillary sentinel lymph node biopsy followed by left axillary lymph node dissection after frozen section pathology demonstrated node-positive disease. Pathology demonstrated multifocal and multicentric invasive lobular carcinoma, grade II (out of III), in a total of four masses comprising a total area of $10 \mathrm{~cm}$. All surgical margins were negative, with 2 (out of 28) lymph nodes sampled positive for metastatic carcinoma (final staging - T2 N1 M0, stage IIB; estrogen receptor and progesterone receptor positive, HER2 negative with a Ki-67 20\%). Interestingly, the left-sided arm urticaria resolved after resection of the breast cancer without any specific intervention.

She received adjuvant dose-dense doxorubicin and cyclophosphamide for 4 cycles followed by 12 weekly doses of paclitaxel. This was followed by radiotherapy to the left reconstructed breast mound and the regional nodal areas. Given the hormone receptor-positive disease, she was started on endocrine therapy in the form of tamoxifen with a plan for a minimum 5 years of adjuvant therapy. She experienced amenorrhea as a result of chemotherapy.

One year after initiation of tamoxifen and 11 months after a normal screening right mammogram, the patient presented again with severe unilateral arm urticaria and associated excoriations, on the contralateral, right, side (fig. 1). This prompted reimaging in the form of a mammogram which showed a $5 \times 3 \mathrm{~mm}$ group of heterogeneous calcification in the right breast at 12 o'clock anterior depth. In addition, there was a 1-mm cluster of calcifications adjacent to the index group. MRI of the breast, however, did not show any features suspicious for malignancy. The mammographic findings led to biopsy of the suspicious calcifications, and pathology showed atypical lobular hyperplasia involving 3 or more foci with columnar cell changes. Calcifications were also noted in benign ducts and in foci of atypical lobular hyperplasia. Given her prior history of urticaria representing a possible PNS, her prior node-positive breast cancer despite optimal screening, as well as the high-risk of future breast cancer based on a diagnosis of multifocal atypia, the consensus was to proceed with what was thought to be a risk-reducing nipple-sparing mastectomy and immediate reconstruction on the right side. Pathology showed multiple foci of atypical lobular hyperplasia and a single focus of grade I invasive tubular carcinoma, $0.3 \mathrm{~cm}$ in greatest dimension (final staging - pT1a NX M0, stage IA; estrogen receptor and progesterone receptor positive, HER2/Neu negative with a Ki-67 0.4\%). There was no indication for adjuvant chemotherapy or postmastectomy radiation; she resumed tamoxifen for adjuvant therapy. The urticaria that was thought to be a paraneoplastic manifestation of the breast cancer again resolved completely and spontaneously after the tumor was resected. 
Kasi et al.: Unilateral Arm Urticaria Presenting as a Paraneoplastic Manifestation of Metachronous Bilateral Breast Cancer

\section{Discussion}

The estimated frequency of PNS in patients with cancer is about 8\% [1]. There are, however, very few studies addressing the incidence of these various PNS in patients with breast cancer and other malignancies [2]. While uncommon, breast cancer can present with varied PNS (table 1). These PNS can range from mild dermatological symptoms to severe neurological complications and respiratory failure [3-7]. From review of the literature, neurological and dermatological manifestations tend to be the more commonly seen paraneoplastic manifestations, albeit both are relatively rare (table 1) [8]. The incidence of various paraneoplastic neurological disorders, for example, was estimated to be around $4 \%$ in all patients with breast cancer [9]. These estimates vary based on the criteria and definitions used to describe these disorders [2].

Other malignancies more commonly associated with paraneoplastic manifestations include lymphoma, gynecologic (ovary) cancers, germ cell tumors, thymomas and lung cancer [10-12]. Observation of these PNS or manifestations without clear etiology should prompt diagnostics to evaluate for underlying cancers as the etiology. The selection of cancer screening procedures should be guided by patient age and risk factors, with emphasis on the more commonly associated malignancies [13].

Early diagnosis in some of these situations is vital to prevent ongoing harm and debility [14]. This, however, is often delayed since the severity of the PNS is not necessarily dependent on the size or stage of the tumor [8].

Treatment and the overall prognosis are variable depending on the severity and presentation of the paraneoplastic manifestation $[8,15]$. Focused efforts to support symptom management and rehabilitation are important considerations to improve quality of life of patients while concurrently diagnosing and treating the underlying malignancy [16]. Removal of the underlying malignancy has been reported to improve or resolve the underlying paraneoplastic process for some of the patients, as in our case $[17,18]$. This, however, does not necessarily abrogate PNS symptoms in all cases.

\section{Conclusions}

PNS, including dermatological manifestations, can present with a wide range of signs and symptoms of variable severity. Diagnosis of the underlying malignancy is often delayed and is not necessarily dependent on the size or stage of the tumor. Knowledge of likely associations with underlying malignancies and age- and risk factor-based appropriate screening in these situations may facilitate prompt diagnosis and treatment of the underlying occult malignancy.

\section{Acknowledgement}

This work was supported by NIH Grant K12 CA90628 (T.C.H.). 


\section{Case Reports in Oncology}

\begin{tabular}{l|l}
\hline Case Rep Oncol 2016;9:33-38 \\
\hline DOI: 10.1159/000443661 & $\begin{array}{l}\text { (c) 2016 The Author(s). Published by S. Karger AG, Basel } \\
\text { www.karger.com/cro }\end{array}$ \\
\hline
\end{tabular}

Kasi et al.: Unilateral Arm Urticaria Presenting as a Paraneoplastic Manifestation of Metachronous Bilateral Breast Cancer

\section{Statement of Ethics}

This study was conducted in accordance with the Declaration of Helsinki. Written informed consent was obtained from the patient. The authors are deeply indebted to the patient for allowing us to share her case as a case report.

\section{Disclosure Statement}

The authors declare that there is no conflict of interest regarding the publication of this article.

\section{References}

1 Pelosof LC, Gerber DE: Paraneoplastic syndromes: an approach to diagnosis and treatment. Mayo Clin Proc 2010;85:838-854.

-2 Rees JH: Paraneoplastic syndromes: when to suspect, how to confirm, and how to manage. J Neurol Neurosurg Psychiatry 2004;75(suppl 2):ii43-ii50.

-3 Sun NZ, Brezinski EA, Berliner J, et al: Updates in adult-onset Still disease: atypical cutaneous manifestations and associations with delayed malignancy. J Am Acad Dermatol 2015;73:294-303.

-4 Taib BG, Kinshuck AJ, Milburn-McNulty P, et al: Opsoclonus-myoclonus syndrome associated with a nasopharyngeal tumor in an adult: a case report. J Med Case Rep 2015;9:128.

5 Alsharabati M, Oh SJ: Paraneoplastic myeloneuropathy in a man with breast cancer. Muscle Nerve 2015;52:685-686.

6 Jaeger B, de Visser M, Aronica E, van der Kooi AJ: Respiratory failure as presenting symptom of necrotizing autoimmune myopathy with anti-melanoma differentiation-associated gene 5 antibodies. Neuromuscul Disord 2015;25:457-460.

7 Protopsaltis I, Drossou A, Katsantonis I, et al: Breast cancer presenting as paraneoplastic erythroderma: an extremely rare case. Case Rep Med 2014;2014:351065.

-8 Rosenfeld MR, Dalmau J: Diagnosis and management of paraneoplastic neurologic disorders. Curr Treat Options Oncol 2013;14:528-538.

9 Croft PB, Wilkinson M: The incidence of carcinomatous neuromyopathy in patients with various types of carcinoma. Brain 1965;88:427-434.

10 Afzal S, Recio M, Shamim S: Paraneoplastic cerebellar ataxia and the paraneoplastic syndromes. Proc (Bayl Univ Med Cent) 2015;28:217-220.

11 Kumar S, Mahajan BB, Kaur S, Singh A: Paraneoplastic dermatomyositis with carcinoma cervix: a rare clinical association. Case Rep Dermatol Med 2014;2014:836246.

-12 Nomani AZ, Wazir M, Kashmir SB, Qureshi MS: Diffuse large B-cell lymphoma of stomach presenting with paraneoplastic cerebellar degeneration syndrome. J Coll Physicians Surg Pak 2014;24(suppl 1):S11-S13.

$\checkmark 13$ Horta ES, Lennon VA, Lachance DH, et al: Neural autoantibody clusters aid diagnosis of cancer. Clin Cancer Res 2014;20:3862-3869.

14 Manger B, Schett G: Palmar fasciitis and polyarthritis syndrome - systematic literature review of 100 cases. Semin Arthritis Rheum 2014;44:105-111.

15 Baizabal-Carvallo JF, Jankovic J: Stiff-person syndrome: insights into a complex autoimmune disorder. J Neurol Neurosurg Psychiatry 2015;86:840-848.

16 Fu JB, Raj VS, Asher A, et al: Inpatient rehabilitation performance of patients with paraneoplastic cerebellar degeneration. Arch Phys Med Rehabil 2014;95:2496-2499.

17 Primiano G, Plantone D, Sauchelli D, et al: Resolution of muscle inflammation after tumor removal in a woman with paraneoplastic dermatomyositis. J Rheumatol 2012;39:2359-2360.

$\longrightarrow 18$ Lekakis L, Tryfonopoulos D, Fakinos G, et al: A case of paraneoplastic autoimmune pancreatitis: mini-review of paraneoplastic syndromes in breast cancer. Anticancer Res 2012;32:3311-3314.

19 Spataro R, La Bella V: Paraneoplastic motor neuron disease associated with breast cancer. Eur J Neurol 2014;21:e5-e6.

20 Kattepur AK, Patil D, Shankarappa A, et al: Anti-NMDAR limbic encephalitis - a clinical curiosity. World J Surg Oncol 2014;12:256.

21 Al-Harbi T, Al-Sarawi A, Binfalah M, Dermime S: Paraneoplastic neuromyelitis optica spectrum disorder associated with stomach carcinoid tumor. Hematol Oncol Stem Cell Ther 2014;7:116-119. 


\section{Case Reports in Oncology}

\begin{tabular}{l|l}
\hline Case Rep Oncol 2016;9:33-38 \\
\hline DOI: 10.1159/000443661 & $\begin{array}{l}\text { (c) 2016 The Author(s). Published by S. Karger AG, Basel } \\
\text { www.karger.com/cro }\end{array}$ \\
\hline
\end{tabular}

Kasi et al.: Unilateral Arm Urticaria Presenting as a Paraneoplastic Manifestation of Metachronous Bilateral Breast Cancer

22 Kannan MA, Sundaram C, Uppin M, et al: Incidence of malignancies in biopsy-proven inflammatory myopathy. Neurol India 2013;61:152-155.

23 Key RG, Root JC: Anti-Yo mediated paraneoplastic cerebellar degeneration in the context of breast cancer: a case report and literature review. Psychooncology 2013;22:2152-2155.

24 Barata PC, Morgado J, Sousa AP, et al: Breast cancer presents with a paraneoplastic neurologic syndrome. Case Rep Oncol 2012;5:616-621.

25 Klaas JP, Ahlskog JE, Pittock SJ, et al: Adult-onset opsoclonus-myoclonus syndrome. Arch Neurol 2012;69:1598-1607.

-26 Dias LP, Faria AL, Scandiuzzi MM, et al: A rare case of severe myositis as paraneoplastic syndrome on breast cancer. World J Surg Oncol 2015;13:134.

27 Kaszewski S, Czajkowski R, Protas-Drozd F, et al: Sweet's syndrome with idiopathic thrombocythemia. Postepy Dermatol Alergol 2014;31:47-52.

28 Reynolds TD, Knights SE: Recurrent metastatic breast cancer presenting with paraneoplastic scleroderma. BMJ Case Rep 2014;2014. pii: bcr2014203575.

29 Ng SS, Teo RY, Seah PP: A case of bullous pemphigoid in a patient with dual cancers, fortuitous or paraneoplastic? Ann Acad Med Singapore 2012;41:313-314.

30 Trisal D, Kumar N, Sundriyal D, Gadpayle AK: Hypercalcaemia of malignancy: two primaries in the same patient. BMJ Case Rep 2014;2014. pii: bcr2014204368.

-31 Richters L, Ortmann M, Faust M, et al: The oncological emergency case: paraneoplastic hypoglycemia in metastatic breast cancer - case report and brief review of the literature. Breast Care 2013;8:368-370.

32 Adamus G: Latest updates on antiretinal autoantibodies associated with vision loss and breast cancer. Investig Ophthalmol Vis Sci 2015;56:1680-1688.

33 Eadie JA, Ip MS, Ver Hoeve JN: Localized retinal manifestations of paraneoplastic autoimmune retinopathy. Retin Cases Brief Rep 2014;8:318-321.

34 Kelly PA, Kuberski C: Stiff person syndrome: a case report. Clin J Oncol Nurs 2014;18:465-467.

Table 1. Commonly reported PNS seen in association with breast cancer

\begin{tabular}{ll}
\hline PNS/manifestations & Recent citations \\
\hline $\begin{array}{l}\text { Neurologic: neuropathy, cerebellar ataxia/degeneration, motor neuron disease, } \\
\text { limbic encephalitis, neuromyelitis optica, opsoclonus-myoclonus syndrome }\end{array}$ & {$[5,8,10,19-25]$} \\
\hline $\begin{array}{l}\text { Dermatologic: rash, erythroderma, dermatitis, dermatomyositis, Sweet syndrome, } \\
\text { scleroderma, bullous pemphigoid, acanthosis }\end{array}$ & {$[7,17,22,26-29]$} \\
\hline $\begin{array}{l}\text { Muscular: myositis, myelopathy } \\
\text { Endocrine: hypercalcemia, hypoglycemia }\end{array}$ & {$[5,6,22,26]$} \\
\hline $\begin{array}{l}\text { Ocular: cancer-associated retinopathy } \\
\text { Other: stiff-person syndrome, adult-onset Still disease, palmar fascitis and } \\
\text { polyarthritis, autoimmune pancreatitis (IgG4 mediated) }\end{array}$ & {$[3,30,31]$} \\
\hline
\end{tabular}




\section{Case Reports in Oncology}

\begin{tabular}{|c|c|}
\hline \multicolumn{2}{|c|}{ Case Rep Oncol 2016;9:33-38 } \\
\hline DOI: 10.1159/000443661 & $\begin{array}{l}\text { (c) } 2016 \text { The Author(s). Published by S. Karger AG, Basel } \\
\text { www.karger.com/cro }\end{array}$ \\
\hline
\end{tabular}

Kasi et al.: Unilateral Arm Urticaria Presenting as a Paraneoplastic Manifestation of Metachronous Bilateral Breast Cancer



Fig. 1. Severe urticaria leading to excoriations presenting as a paraneoplastic manifestation of breast cancer in a 49-year-old woman. 